\title{
Late onset seizures and progressive cognitive decline: is it an arachnoid cyst?
}

\author{
Osama S M Amin
}

Department of Neurology, Sulaimaniya General Teaching Hospital, Sulaimaniya City, Iraq

\section{Correspondence to} Dr Osama S M Amin, dr.osama.amin@gmail.com

\section{DESCRIPTION}

A 65-year-old man has been experiencing recurrent generalised tonic-clonic seizures since few months. He has a slowly progressive cognitive decline since many years. There is spastic left-sided hemiparesis. His elder sister says that his left side has been weak since birth. The family denied any history of head trauma. He was neither hypertensive nor diabetic. They reside in a village near Iraq-Iran border. His blood tests and 12-lead ECG were unremarkable. An urgent non-contrast CT scan of the brain was performed (figure 1). A diagnosis of symptomatic seizures secondary to an old right middle cerebral artery territory ischaemic stroke was made and he was treated accordingly. However, his MRI examination of the brain, which was performed 2 weeks later, uncovers the correct culprit (figure 2).
An arachnoid cyst forms when the cerebrospinal fluid (CSF) collects itself between the two layers of the arachnoid matter, which may be primary (owing to a developmental anomaly) or secondary to an inflammatory process. Arachnoid cysts comprise approximately $1 \%$ of all intracranial masses (42\% of them are supratentorial) and may enlarge over time; they may communicate with the rest of the subarachnoid spaces, but never directly communicate with the ventricular system.

Headache, seizures, focal deficits and cognitive impairment are the usual manifestations in symptomatic ones. In adults, arachnoid cysts have been found to result in low employment status, decreased quality of life scores and prevalent symptoms of anxiety. This patient's cyst is responsible for his longstanding spastic hemiparesis, cognitive decline and late onset seizures; the CT image of the brain deceived us. ${ }^{1-3}$
To cite: Amin OSM. BMJ Case Rep Published online: [please include Day Month Year] doi:10.1136/bcr-2013009847

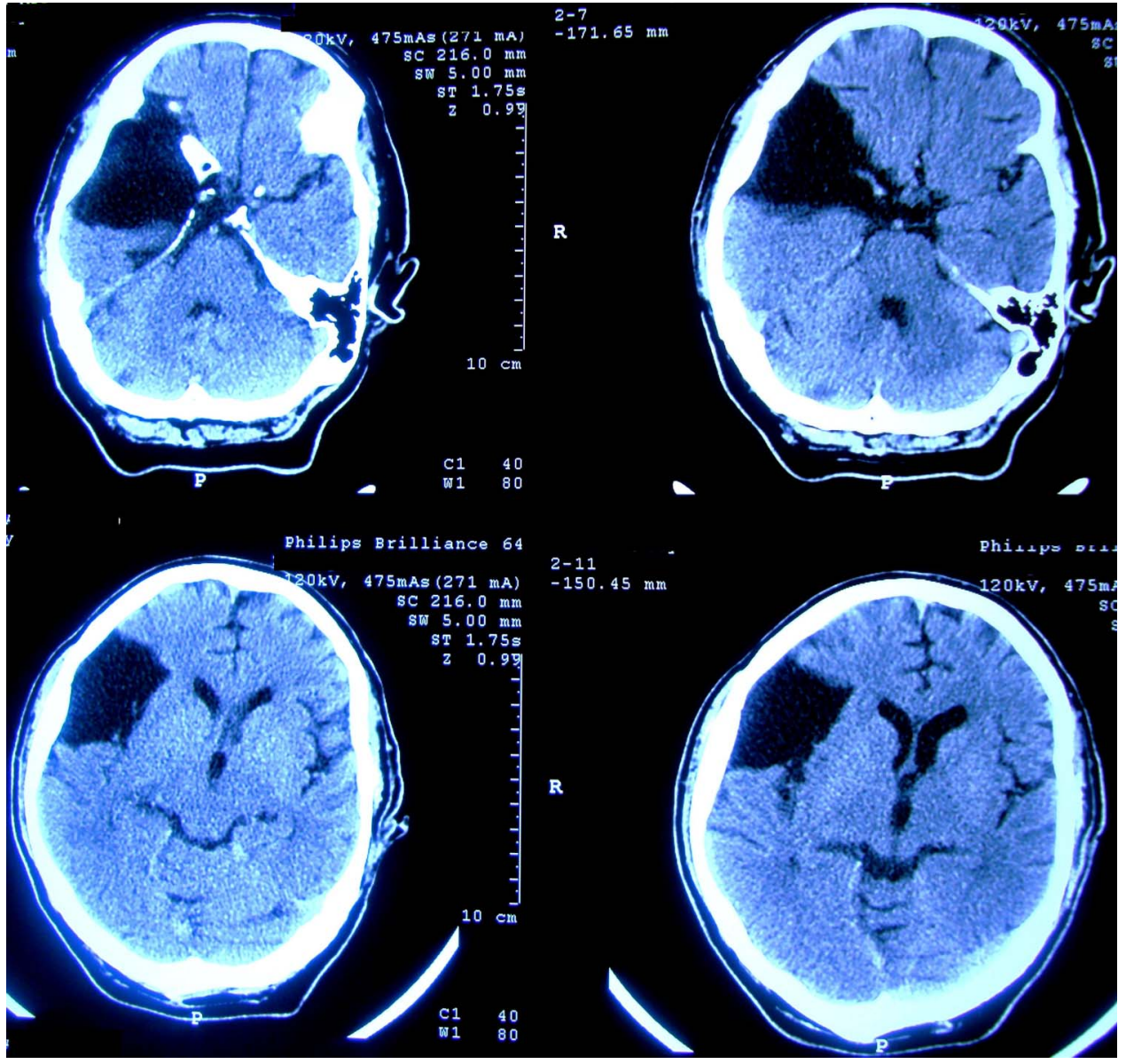

Figure 1 Non-contrast CT scan of the brain of the patient at the time of A\&E admission. Note the highly demarcated hypodense area at the right fronto-temporal lobes; a diagnosis of old right middle cerebral artery territory infarction was made. 


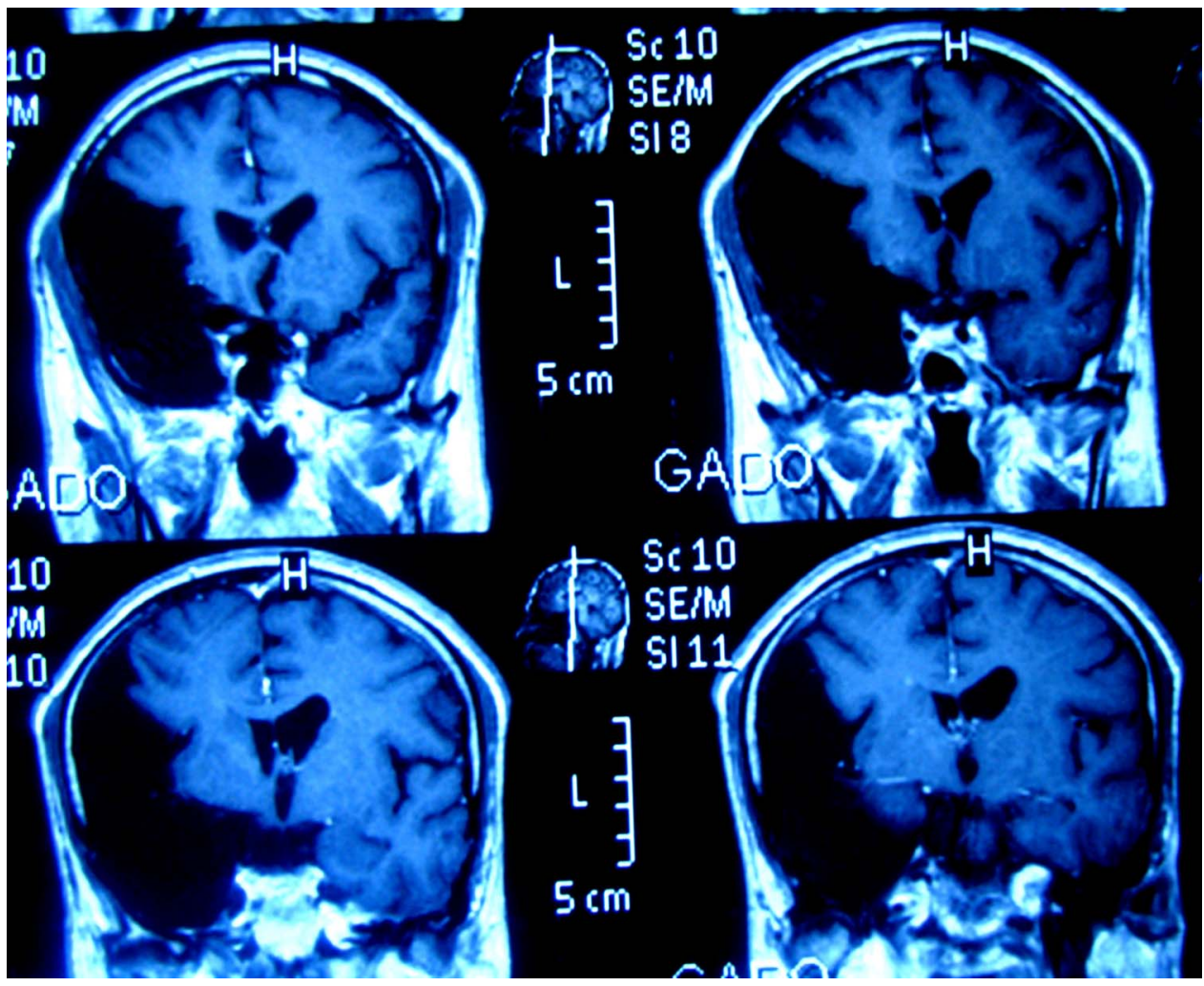

Figure 2 Coronal T1-wieghted MRI image with gadolinium. Note how large the arachnoid cyst is. It has replaced parts of the right frontoparietal lobes and all of the right temporal lobe.

\section{Learning points}

- Arachnoid cysts may be entirely asymptomatic or may result in a variable combination of headache, seizures, focal deficits and cognitive decline.

- Their radiological appearance may mislead the physician to think of old infarction or cystic tumours.
Patient consent Obtained.

Provenance and peer review Not commissioned; externally peer reviewed.

\section{REFERENCES}

1 Amin OSM, Shwani SS. Asymptomatic supratentorial arachnoid cyst and symptomatic demyelination plaques: which one needs treatment? BMJ Case Rep 2010;10.1136 bcr.08.2010.3286

2 Beri S, Khan A, Gosalakkal J, et al. Arachnoid cysts: are they always incidental? BM Case Rep 2011;10.1136/bcr.06.2011.4348

3 Rafiq MK. Arachnoid cyst masquerading as Alzheimer's disease. BMJ Case Rep 2009;10.1136/bcr.11.2008.1284

Competing interests None.

Copyright 2013 BMJ Publishing Group. All rights reserved. For permission to reuse any of this content visit http://group.bmi.com/group/rights-licensing/permissions.

BMJ Case Report Fellows may re-use this article for personal use and teaching without any further permission.

Become a Fellow of BMJ Case Reports today and you can

- Submit as many cases as you like

- Enjoy fast sympathetic peer review and rapid publication of accepted articles

- Access all the published articles

- Re-use any of the published material for personal use and teaching without further permission

For information on Institutional Fellowships contact consortiasales@bmjgroup.com

Visit casereports.bmi.com for more articles like this and to become a Fellow 